\title{
Epidemiology and the role of antioxidants in preventing coronary heart disease: a brief overview
}

\author{
BY RUDOLPH A. RIEMERSMA \\ Cardiovascular Research Unit, University of Edinburgh, Hugh Robson Building, George Square, \\ Edinburgh EH8 $9 X F$
}

Coronary heart disease (CHD) is the principal cause of premature death in the Western world. Early epidemiological studies have implicated dietary saturated fat, presumably due to its serum cholesterol-raising effect, as an important risk factor. However, cholesterol and other classical risk factors, such as blood pressure, do not fully explain an individual's risk of CHD (Heller et al. 1984).

The theory that the balance between factors that promote free-radical-mediated oxidation and the antioxidant defence mechanisms (i.e. 'oxidative stress') may be a specific risk factor for CHD (Steinberg et al. 1989) has gained more acceptance. The aim of the present brief review is to examine critically the recent epidemiological evidence.

\section{ATHEROSCLEROSIS AND LIPID PEROXIDATION IN VIVO}

It is not the purpose of the present mini-review to examine all direct and indirect evidence in the greatest possible detail. Nevertheless, when considering the possible role of antioxidant vitamins in the prevention of atherosclerosis an appreciation of the fact that not all low-density lipoproteins (LDL) are equally atherogenic is required. LDL particles require some oxidative modification before they become truly atherogenic, vasoconstrictive and enhance platelet aggregation and, thus, thrombosis. Most of the evidence is derived from artificially oxidized lipoprotein particles in vitro or from experiments using so-called 'specific' drugs with antioxidant properties.

The difficulty in testing this hypothesis is that highly reactive free radicals have a short half-life and there are several defence mechanisms (superoxide dismutase (EC 1.15.1.1), glutathione peroxidase (EC 1.11.1.9) and dietary antioxidant vitamins (vitamins $\mathrm{C}$ and $\mathrm{E}$ or $\beta$-carotene) and polyphenols) which can terminate free-radical chain reactions in the water or lipid phase. Methods employing chemical free-radical spin-traps cannot be used in clinical settings, and give little or no information about the nature of the reactive species in animal studies in vivo. In addition, the possibility of artefactual formation of lipid peroxides ex vivo presents a serious methodological problem.

Yet there is evidence, some of it more convincing than the rest, that lipid peroxides occur in atherosclerotic lesions and perhaps even in plasma. Levels of thiobarbituric acid reactive substances (TBARS), such as malondialdehyde, formed from lipid peroxides are higher in patients with acute myocardial infarction than in healthy controls (Stringer et al. 1989). However, the use of TBARS as a measure of in vivo lipid peroxidation has fallen into disrepute, due to its lack of specificity and the formation of aldehydic material formed during the test. Coronary atherosclerosis in Swedish patients with a first acute myocardial infarction is more severe in those in whom LDL-lipid peroxidation is readily induced in vitro (Regnström et al. 1992). Unfortunately, neither the levels of antioxidant vitamins nor those of polyunsaturated fatty acids, the substrate for lipid peroxidation, 
Table 1. Characteristics and strength of epidemiological evidence

\begin{tabular}{lcc}
\hline \hline & Type of study & Strength \\
\hline Cross-cultural & $+1-$ \\
Cross-sectional: & + \\
Healthy subjects & ++ \\
Case-control & +++ \\
Longitudinal & +++ \\
\hline
\end{tabular}

were measured in that study. Avogaro et al. (1988) isolated plasma 'oxidized' or 'oxidatively modified' LDL with its characteristically increased negative charge during electrophoresis. In his hands the composition of this fraction differs from LDL oxidized in vitro. Re-isolation of native (i.e. not oxidized) LDL does not yield a similar fraction with increased electrophoretic mobility. The presence of 'oxidized' LDL in plasma does not imply the site of formation, a fact recognized by these authors. They suggest that these modified particles may be in process of reverse transport of oxidized lipids to the liver. LDL isolated with gentle procedures from atherosclerotic lesions has many of the characteristics of LDL oxidized in vitro (Ylä-Herttuala et al. 1989). Antibodies against epitopes of oxidized LDL recognize material in human (and rabbit) atherosclerotic lesions (Palinski et al. 1989; Ylä-Herttuala et al. 1990), and are localized at sites where macrophage derived foam cells are found. It concerns, however, observations in a relatively small number of patients. More convincing is perhaps the presence of auto-antibodies against oxidized LDL in human serum (Palinski et al. 1989; Salonen et al. 1992). These titres are higher in patients with carotid atherosclerosis than in controls (Salonen et al. 1992). A relationship between auto-antibody titres and smoking was observed. The titres were also related to the progression of the carotid lesions over a 2-year period, suggesting that they reflect 'active' arterial disease.

\section{EPIDEMIOLOGICAL EVIDENCE}

The nature of epidemiological studies examining the relationship between dietary and plasma antioxidant vitamins and CHD varies considerably. On the one hand there are large surveys in which information is almost entirely obtained by self-administered questionnaire. Other studies, with actual plasma or tissue antioxidant levels as well as measures of classical risk factors, tend to be relatively small. Epidemiological studies also differ in other aspects (Table 1). Thus, differences in risk factors in population samples of various countries, although related to CHD mortality rates, could be due to many other factors, whether known or not. As in cross-sectional studies of healthy populations, perhaps only $30 \%$ may develop CHD and then many years later. Comparisons of risk factors between cases and apparently healthy controls does not suffer from uncertainty in case definition, but subclinical CHD may be prevalent in many controls, thereby reducing the overall contrast between the two groups. Case fatality and disease modification of risk factor levels during the acute phase could seriously affect the results of these studies too. Long-term follow-up of healthy subjects with known risk factor levels is probably the most feasible design provided risk factors are stable. The ultimate 
test is whether CHD can be prevented by long-term intervention. Therefore, it should not surprise anyone that the strength of the evidence ranges from the plausible to almost certain proof.

The view that fruit and vegetables protect against coronary or cerebro-vascular disease is not new. Regional standardized mortality ratios of CHD in the UK relate inversely to calculated vitamin $\mathrm{C}$ intake, reflecting a long-established regional gradient in lifestyle and social circumstances (Knox et al. 1973). In Scotland, where CHD mortality is high, little fruit and green vegetables are eaten (Smith et al. 1989).

\section{CROSS-CULTURAL AND CROSS-SECTIONAL STUDIES}

Plasma antioxidant vitamins $\mathrm{C}$ and $\mathrm{E}$ and carotene (predominantly $\beta$-carotene) were measured in four randomly-selected populations from North Karelia, South West Finland, Scotland and Italy with differing CHD mortality rates (Riemersma et al. 1990). Centralized laboratory analysis was carried out to prevent systematic errors. No consistent relationship with CHD was observed, for instance carotene was low in Scotland in comparison with Italy and Finland. Furthermore, levels did not differ between the high and moderately high CHD areas in Finland. Vitamin E levels differed between the four areas. After adjustment for differing cholesterol levels, low vitamin $\mathrm{E}$ was a common feature in Northern Europe but failed to explain the gradients in CHD mortality. This study was expanded to sixteen cohorts (Gey et al. 1991). Vitamins C and $\mathrm{E}$ (cholesterol-adjusted) were both inversely related to regional $\mathrm{CHD}$ mortality rates $r-0.79$ and $r-0.36$. The relationship between CHD and carotene was weaker. After adjustment for differences in classical risk factors such as serum cholesterol and diastolic blood pressure in multivariate analysis only the relationship between low vitamin $E$ levels and CHD mortality remained significant. The relationship with carotene and vitamin $\mathrm{C}$ was significant when the results from the Finnish populations were omitted in subsequent analysis of the same data (Gey et al. 1993). It was not possible to exclude the confounding influence of dietary linoleic acid, which in itself is inversely related to the risk of CHD (Oliver et al. 1990).

Vitamin $C$ levels in leucocytes are low in patients with an acute myocardial infarction (Hulme et al. 1972). An acute-phase response is the most likely explanation for this observation as all antioxidant levels are very low during the first days after the heart attack (R. A. Riemersma, unpublished results). Men with significant coronary artery obstructions and regional wall kinetic abnormalities had lower leucocyte vitamin $\mathrm{C}$ levels than those with normal arteriograms, irrespective of smoking status (Ramirez \& Flowers, 1980). On the other hand neither plasma vitamin C nor cholesterol-adjusted vitamin $\mathrm{E}$ differed between those with and without $\mathrm{CHD}$ defined on the basis of symptoms, a history of CHD, or objective evidence of ischaemia on a bicycle ergometer exercise test (Salonen et al. 1988). Antioxidant vitamins $C$ and $E$ as well as carotene were lower in new cases of angina discovered by screening a large population sample in Edinburgh (Riemersma et al. 1991). The odds ratio for angina for men whose levels fell in the lowest quintile relative to the highest quintile of the normal distribution of plasma vitamin $E$ in Edinburgh was 2.51 (confidence intervals (CI) 1.24-5.10). The odds ratio rose to 2.68 (CI 1.07-6.70) after adjustment for total cholesterol and other classical risk factors and the overall trend was significant $(P=0.02)$. The unadjusted odds ratios for angina subjects with lowest concentrations of plasma vitamin $\mathrm{C}$ and of carotene were 
$2 \cdot 35$ (CI 1.16-4.78) and 2.64 (CI 1.32-5.29) respectively. The strength of these inverse relationships was reduced and they were no longer significant after adjustment for smoking and other risk factors. Thus, low plasma levels of vitamins $\mathrm{C}$ and $\mathrm{E}$ (and diets poor in fresh fruit and green vegetables) are associated with a higher risk of CHD. Such diets are more common in areas of material deprivation.

We have previously reported an inverse relationship between adipose linoleic acid and the risk of angina in this population (Wood et al. 1987). Plasma vitamin $E$ is related to adipose linoleate levels $(r 0.31, P<0 \cdot 001)$. The inverse relationship between plasma vitamin $E$ and the likelihood of angina was examined, therefore, in relation to this fatty acid. When it was included in the logistic analysis for vitamin $\mathrm{E}$, adipose linoleate made an independent contribution to the explanation of angina $(P<0 \cdot 01)$, but vitamin $\mathrm{E}$ did not $(P<0.09)$. The fact that these factors are almost independent of each other is remarkable in view of their common food source. The reasons are not understood but could possibly be due to the fact that antioxidants are more easily destroyed by food processing than polyunsaturated fatty acids (Esterbauer et al. 1987). The relationship between vitamin $\mathrm{E}$ and carotene and a first acute myocardial infarction has been re-examined in a multicentre case-control study (Kardinaal et al. 1993). Adipose tissue levels were used to avoid the acute-phase problem. Carotene but not vitamin $\mathrm{E}$ was inversely related to the risk of acute infarction (relative risk $1 \cdot 89,95 \% \mathrm{CI} 1 \cdot 14-3 \cdot 13$, $P<0.05$ ), independently of history of hypertension, total cholesterol and smoking habit. However, it appears that there are regional differences in Europe since low vitamin $\mathrm{E}$ was associated with increased risk of acute myocardial infarction in Scotland (R. A. Riemersma, unpublished results).

\section{LONGITUDINAL STUDIES}

Prospective studies of the relationship between vitamin E levels and CHD mortality in individuals have found no significant relationships (Salonen et al. 1985; Kok et al. 1987). In these studies vitamin E levels were measured in samples stored long term. Levels were very low suggesting that significant losses had occurred, making the results doubtful. The Basle Prospective study of 3000 pharmaceutical employees did not suffer from this problem, as all vitamin measurements (vitamins $\mathrm{C}$ and $\mathrm{E}$, carotene) were measured on entry into the study. The relative risk of ischaemic heart disease for men with low plasma carotene levels $(<0.23 \mu \mathrm{M})$ was 1.53 (CI 1.07-2.20, $P=0.024$; Gey et al. 1987). The risk for men with low vitamin $C$ was $25 \%$ higher, but this was not significant. Few men had vitamin E levels below the 'optimal' target of 27.5-30 $\mathrm{M}$ and according to the authors this did not lend itself to evaluate whether low vitamin E predisposes to CHD. However, the optimal level is apparently determined from observed relationships with disease or mortality and lacks a firm theoretical basis that justifies a threshold effect. What is important is that all these studies were undertaken at a time when dietary advice to reduce $\mathrm{CHD}$ did not consider a role of antioxidants.

Another study used a $24 \mathrm{~h}$ dietary recall method to calculate vitamin $\mathrm{C}$ intake in Swedish women initially free of $\mathrm{CHD}$. There was no relationship between dietary vitamin $\mathrm{C}$ and vascular disease (myocardial infarction, stroke and death; Lapidus et al. 1986). Several recent studies all conducted in the USA have re-examined this. Men who regularly take vitamin $\mathrm{C}$ supplements had almost $40 \%$ reduction in age-standardized mortality from CHD (Enström et al. 1992). In this study the relationship to vitamin $\mathrm{E}$ 
was not considered, but in two subsequent studies from Harvard using food-frequency questionnaires it was considered. Male health professionals and female nurses taking large vitamin E supplements had fewer coronary events (Rimm et al. 1993; Stampfer et al. 1993) irrespective of other antioxidants (vitamin C and $\beta$-carotene). A 29 and $17 \%$ reduction in coronary events was observed in doctors with the highest $\beta$-carotene and vitamin $C$ intake, although it was only significant in the former. The relationships for vitamin $C$ and $\beta$-carotene were not examined separately in the nurses' study. Vitamin $E$ intake without supplements is poorly related to total dietary vitamin $E$. Men with the highest dietary vitamin $\mathrm{E}$ had a reduced relative risk of coronary events but the trend for an association was not significant $(P=0 \cdot 11)$. In contrast almost all $\beta$-carotene originates from dietary sources in this study and, therefore, the reduced risk provided by $\beta$-carotene is of greater significance for public health.

However, there are important limitations to all these studies. American men and women who regularly take large vitamin supplements differ from those who do not take supplements in terms of education, smoking habit, physical activity, use of aspirin. Thus, it appears that vitamin supplements are closely related to lifestyle and it may not be possible to correct for the many confounding factors that this entails. The question remains whether these questionnaires classify total dietary vitamin use of subjects accurately. Alternatively it may not be the dietary intake that matters if other factors significantly modify tissue, plasma or LDL levels (smoking, dietary fat, bioavailability, or perhaps even genetic factors, etc.).

\section{INTERVENTION TRIALS}

To date the results of one intervention trial with $25 \mathrm{mg} \beta$-carotene have been published in the form of an abstract. In this study $\beta$-carotene was associated with a reduced incidence of coronary events but the number of cases was very small (Gaziano et al. 1990). The results of one study of the effect of $50 \mathrm{mg}$ vitamin $E$ or $25 \mathrm{mg} \beta$-carotene either alone or in combination in smokers should become available soon (ATBC trial). Several other studies are planned and the tendency is to use large supplements that bear no resemblance to dietary intake, a trend no doubt encouraged by the lack of toxicity of vitamins $\mathrm{E}$ and $\mathrm{C}$ and $\beta$-carotene. Of course this may increase the likelihood of a significant result, but the importance of dietary antioxidants in the prevention of CHD will not be answered.

\section{CONCLUSION}

Experimental studies show that antioxidants in general can prevent aortic atherosclerotic lesions and argue strongly in favour of a protective role of antioxidant vitamins in the development of atherosclerosis. However, the risk factors for aortic and coronary atherosclerosis are not identical and coronary atherosclerosis is only one aspect of CHD.

This review largely concentrated on the epidemiological evidence. The data suggest an inverse association between $\mathrm{CHD}$ mortality and antioxidant vitamins $\mathrm{C}$ and $\mathrm{E}$, as well as carotene. However, this relationship is not observed in all countries studied. In Scotland a consistent relationship is observed between low levels of plasma and adipose vitamin $\mathrm{E}$ and risk of CHD. Other studies, from the USA, suggest a benefit from high intakes of vitamins $\mathrm{C}$ and $\mathrm{E}$ in doses much larger than necessary to prevent deficiency diseases. But 
these equally point at lifestyle as a recognized factor for the development of CHD. Formal double-blind intervention trials using vitamins $\mathrm{C}$ or $\mathrm{E}$ have not been conducted and tend to use doses that bear no resemblance to dietary levels of antioxidant vitamins. Firm dietary recommendations to prevent CHD cannot be given on the basis of current evidence.

\section{REFERENCES}

Avogaro, P., Bon, G. B. \& Cazzolato, G. (1988). Presence of a modified low-density lipoprotein in humans. Arteriosclerosis 8, 79-87.

Enström, J. E., Kanim, L. E. \& Klein, M. A. (1992). Vitamin C intake and mortality among a sample of the United States population. Epidemiology 3, 194-202.

Esterbauer, H., Jurgens, G., Quehenberger, O. \& Koller, E. (1987). Autoxidation of human low density lipoprotein: loss of polyunsaturated fatty acids and vitamin $\mathrm{E}$ and generation of aldehydes. Journal of Lipid Research 28, 495-509.

Gaziano, J. M., Manson, J. E., Ridker, P. M., Buring, J. E. \& Hennekens, C. H. (1990). Beta carotene therapy for chronic stable angina. Circulation 82, Suppl. III, 201, Abstr. 0796.

Gey, K. F., Moser, U. K., Jordan, P., Stähelin, H. B., Eichholzer, M. \& Ludin, E. (1993). Increased risk of cardiovascular disease at suboptimal plasma concentrations of essential antioxidants: epidemiological update with special attention to carotene and vitamin C. American Journal of Clinical Nutrition 57, Suppl. 5, 787S-797S.

Gey, K. F., Puska, P., Jordan, P. \& Moser, U. K. (1991). Inverse correlation between plasma vitamin E and mortality from ischaemic heart disease in cross-cultural epidemiology. American Journal of Clinical Nutrition 53, 326S-334S.

Gey, K. F., Stähelin, H. B., Puska, P. \& Evans, A. (1987). Relationship of plasma level of vitamin C to mortality from ischaemic heart disease. Annals of New York Academy of Sciences 498, 110-123.

Heller, R. F., Chinn, S., Tunstall-Pedoe, H. D. \& Rose, G. (1984). How well can we predict heart disease? Findings in the United Kingdom Heart Disease Prevention Project. British Medical Journal 288, 1409-1411.

Hulme, R., Weyers, E., Rowan, T., Reid, D. S. \& Hillis, W. S. (1972). Leucocyte ascorbic acid levels after acute myocardial infarction. British Heart Journal 34, 238-243.

Kardinaal, A. F. M., Kok, F. J., Ringstad, J., Gomez-Aracena, J., Mazaev, V. P., Kohlmeier, L., Martin, B. C., Ara, A., Kark, J. D., Delgado-Rodriguez, M., Riemersma, R. A., van 't Veer, P., Huttunen, J. K. \& Martin-Moreno, J. M. (1993). Antioxidants in adipose tissue and risk of myocardial infarction: The Euramic Study. Lancet 342, 1379-1384.

Knox, E. G. (1973). Ischaemic heart disease mortality and dietary intake of calcium. Lancet i, 1465-1467.

Kok, F. J., de Bruin, A. M., Vanmeeren, R., Hoffman, A., van Laar, A., de Bruin, M., Hermus, R. J. J. \& Valkenburg, H. A. (1987). Serum selenium, vitamin antioxidants and cardiovascular mortality: a 9-year follow-up study in The Netherlands. American Journal of Clinical Nutrition 45, 462-468.

Lapidus, L., Andersson, H., Bengtsson, C. \& Bosaeus, I. (1986). Dietary habits in relation to incidence of cardiovascular disease and death in women: a 12-year follow-up of participants in the population study of women in Gothenburg, Sweden. American Journal of Clinical Nutrition 44, 444-448.

Oliver, M. F., Riemersma, R. A., Thomson, M., Fulton, M., Abraham, R. A. \& Wood, D. A. (1990). Linoleic acid and coronary heart disease. In Omega-6 Essential Fatty Acid: Pathophysiology and Roles in Clinical Medicine, pp. 121-126 [D. Horrobin, editor]. New York: Alan R. Liss Inc.

Palinski, W., Rosenfeld, M. E., Ylä-Herttuala, S., Gurtner, G. C., Socher, S. S., Butler, S. W., Parthasarathy, S., Carew, T. E., Steinberg, D. \& Witztum, J. L. (1989). Low-density lipoprotein undergoes oxidative modification in vivo. Proceedings of the National Academy of Sciences, USA 86, 1372-1376.

Ramirez, J. \& Flowers, N. C. (1980). Leucocyte ascorbic acid and its relationship to coronary artery disease in man. American Journal of Clinical Nutrition 33, 2079-2087.

Regnström, J., Nilsson, J., Tornvall, P., Landou, C. \& Hamsten, A. (1992). Susceptibility to low-density lipoprotein oxidation and coronary atherosclerosis in man. Lancet 339, 1183-1186.

Riemersma, R. A., Oliver, M., Elton, R. A., Alfthan, G., Vertianinen, E., Salo, M., Rubba, P., Mancini, M., Georgi, H., Vuilleumier, J.-P. \& Gey, K. F. (1990). Plasma antioxidants and coronary heart disease: vitamins $C$ and E, and selenium. European Journal of Clinical Nutrition 44, 143-150.

Riemersma, R. A., Wood, D. A., MacIntyre, C. C. A., Elton, R. A., Gey, K. F. \& Oliver, M. F. (1991). Risk of angina pectoris and plasma concentrations of vitamins $A, C$ and $E$ and carotene. Lancet 337, 1-5. 
Rimm, E. B., Stampfer, M. J., Ascerio, A., Gionannucci, E., Colditz, G. A. \& Willett, W. C. (1993). Vitamin $\mathrm{E}$ consumption and the risk of coronary heart disease in men. New England Journal of Medicine 328, 1450-1456.

Salonen, J. T., Salonen, R., Penttilä, I., Harranen, J., Jauhiainen, M., Mäenpää, P. H., Alfthan, G. \& Puska, P. (1985). Serum fatty acids, apolipoproteins, selenium and vitamin antioxidants and the risk of death from coronary heart disease. American Journal of Cardiology 56, 226-231.

Salonen, J. T., Salonen, R., Seppänen, K., Kantola, M., Parvainen, M., Alfthan, G., Mäenpää, P. H., Taskinen, E. \& Rauramaa, R. (1988). Relationship of serum selenium and antioxidants to plasma lipoproteins, platelet aggregability and prevalent ischaemic heart disease in Eastern Finnish men. Atherosclerosis 70, 155-160.

Salonen, J. T., Ylä-Herttuala, S., Yamamoto, R., Butler, S., Korpela, H., Salonen, R., Nyyssönen, K., Palinski, W. \& Witzum, J. L. (1992). Autoantibody against oxidised LDL and progression of carotid atherosclerosis. Lancet 339, 883-887.

Smith, W. C. S., Tunstall-Pedoe, H., Crombie, I. K. \& Tavendale, R. (1989). Concomitants of excess coronary deaths - major risk factor and lifestyle findings from 10359 men and women in the Scottish Heart Health Study. Scottish Medical Journal 34, 550-555.

Stampfer, M. J., Hennekens, C. H., Manson, J., Colditz, G. A., Rosner, B. \& Willett, W. C. (1993). Vitamin $\mathrm{E}$ consumption and the risk of coronary heart disease in man. New England Journal of Medicine 328, 1444-1449.

Steinberg, D., Parthasarathy, S., Carew, T. E., Khoo, J. C. \& Witztum, J. L. (1989), Beyond cholesterol: modifications of low-density lipoprotein that increases its atherogenicity. New England Journal of Medicine 320, 915-924.

Stringer, M. D., Görög, P. G., Freeman, A. \& Kakkar, V. V. (1989). Lipid peroxides and atherosclerosis. British Medical Journal 298, 281-284.

Wood, D. A., Butler, S., MacIntyre, C., Riemersma, R. A., Thomson, M., Elton, R. A. \& Oliver. M. F. (1987). Linoleic and eicosapentaenoic acids in adipose tissue and platelets and risk of coronary heart disease. Lancet i, 177-183.

Ylä-Herttuala, S., Palinski, W., Rosenfeld, M. E., Parthasarathy, S., Carew, T. E., Butler, S., Witztum, J. L. \& Steinberg, D. (1989). Evidence for the presence of oxidatively modified low density lipoprotein in atherosclerotic lesions of rabbit and man. Journal of Clinical Investigation 84, 1086-1095.

Ylä-Herttuala, S., Rosenfeld, M. E., Parathasarathy, S., Glass, C. K., Sigal, E., Witztum, J. L. \& Steinberg, D. (1990). Colocalization of 15-lipoxygenase messenger-RNA and protein with epitopes of oxidized low-density-lipoprotein in microphage-rich areas of atherosclerotic lesions. Proceedings of the National Academy of Sciences, USA 87, 6959-6963. 